\title{
Research on Recruitment Problems and Countermeasures in Enterprise Human Resource Management - Take Shenzhen Paijie Company as an Example
}

\author{
Xiaoyuan $\mathrm{Li}^{1, \mathrm{a}, *}$ and Zhiqian Wang ${ }^{2, \mathrm{~b}}$
}

\author{
${ }^{1}$ Business School, Jiangxi Normal University, Nanchang, Jiangxi, China \\ ${ }^{2}$ Jiangxi Economic Development Research Institute, Jiangxi Normal University, Nanchang, Jiangxi, China \\ alxy_0409@163.com, ${ }^{b} 624722906 @ q q . c o m$ \\ *corresponding author
}

\begin{abstract}
With the rapid development of economy, new enterprises are springing up. The arrival of the Internet era and the application of big data have brought new opportunities and challenges for the development of enterprises. With the development and progress of electronic technology and information technology, electronic technology industry also had the new change, in all aspects of human life can see electronic technology products. At the same time, fierce competition in the industry are increasing, technology innovation and talent development become the core element of the electronic science and technology competition among the enterprises, enterprise recruitment management plays an increasingly important role. But now most managers have inadequate understanding of human resources recruitment, the recruitment methods adopted and the recruitment system established are not scientific enough and hinder the long-term development of enterprises.. Shenzhen peijie company is a typical electronic science and technology enterprise, specializing in the development, production, sales and service of circuit board testing equipment, is a senior professional solution provider in the field of electronic equipment testing.Based on the relevant theoretical knowledge of human resource management, this paper adopts case study method, literature study method and survey method to discuss the human resource recruitment management, analyzes the current situation and existing problems of paijie's recruitment management, and proposes specific solutions.
\end{abstract}

Keywords: human resources, recruitment management, problems, countermeasures

\section{INTRODUCTION}

In fact, the competition between enterprises is the competition among talents. Therefore, it is particularly important for enterprises to obtain more talent resources. Recruitment is an important way for enterprises to obtain high-quality talents.At present, most enterprises have inadequately understood the human resource recruitment, the effectiveness of recruitment and the promotion of enterprise development is not enough. The unscientific recruitment way makes the enterprise recruitment cost significantly increased, consumed the enterprise's human, material and financial resources.In this context, it is particularly important and urgent to improve the recruitment methods and recruitment system for the further development of enterprises and the reduction of operating costs.

This article is based on the theme of human resources recruitment management and take shenzhen company as an example, investigated the company's situation of human resources recruitment, combined with the previous literature, found out the enterprise's recruitment deficiency, and put forward the corresponding countermeasures, thus to provide guidance to the company's recruitment work. This paper has enriched the theories related to human resource recruitment, provided theoretical guidance for paijie company, and has theoretical guidance significance for similar electronic technology companies and promoting the recruitment practice of the same type of electronic technology companies.

\section{LITERATURE REVIEW}

Combined with the previous literature, the research on talent recruitment mainly focuses on the following aspects: the existing problems in current recruitment, the effectiveness of recruitment and the employee competency.

\subsection{Research on Recruitment Management}

Recruitment is an important part of human resource management and the first step in human resource management. However, many people still have insufficient understanding of recruitment. Liu hongjuan[2] pointed out that with the improvement of economic level, enterprises are facing new challenges in talent recruitment. In the new era, enterprises' human resource recruitment has problems such as imperfect planning, lack of attention to internal talents and low professional level of recruitment departments. Bai rengchu[1] further pointed out that in the enterprise 
recruitment management, there are still some problems such as the lack of standardization of job requirements description and the interview process. The importance of talents is increasingly prominent, and the role of recruitment for enterprises is also increasingly important. However, in most small and medium-sized enterprises, managers fail to establish a correct concept of human resource management.

\subsection{Research on the Effectiveness of Recruitment}

For enterprises, the effectiveness of recruitment cannot be ignored to reduce the brain drain, save enterprise resources and reduce enterprise costs. Effective recruitment can not only guarantee enterprises to obtain high-quality talents, but also establish a good image for enterprises[3]. Benson[6] proposed in his research that the recruitment effect would be directly affected by the recruitment channels employed by enterprises. Therefore, enterprises should make recruitment channels more diversified and improve the existing recruitment process, so as to reduce the cost of enterprises and improve the operation efficiency of enterprises.

\subsection{Research on Employee Competency}

Previous research on recruitment models mainly analyzed the recruitment of enterprises based on the competency model. Bueno and Tubbs[5] believe that the global leadership model contains many competency elements, among which six are the most important: cross-cultural communication, cross-cultural interpersonal sensitivity, internal driving force of learning, respect for others, flexibility and openness. Zhang junlin[4] pointed out in his article that the company attaches more importance to the ability and quality of employees and has higher requirements on the evaluation of their personal quality. The company should do a good job in job analysis. He further pointed out that the competency model is mainly applied in three aspects in the recruitment of enterprises -- the release of recruitment information, the design of job application form and the design of interview process.

Based on the above research results, it can be seen that most of the previous studies focused on relevant influencing factors. In addition, most of the articles were theoretical, and there was a lack of in-depth research on enterprise talent recruitment and specific analysis on the process of enterprise talent management recruitment. This paper will focus on operability according to the actual situation of the enterprise, and take paijie company as an example to carry out research.

\section{DATA SOURCES}

This paper mainly uses the interview method to interview six employees of paijie company to understand the company's recruitment and employees' work.

\subsection{Research Methods}

This paper mainly adopts the interview method to conduct research, collect data through the interview, understand the company's recruitment time, recruitment channel, interview process and job requirements, finally summarize and analyze the data to form a written document.

\subsection{Respondents}

This paper mainly investigates six employees of paijie company, including two senior managers, one hr specialist, one intern and one veteran employee who has worked for more than two years. In the survey sample, there are three men and three women, two over 40 years old, two between 30-40 years old, two between 20-30 years old, three undergraduates, two junior college students and one secondary school student.

\section{ANALYSIS OF RECRUITMENT MANAGEMENT PROBLEMS IN PAIJIE COMPANY}

Since its establishment in 2004, Shenzhen paijie Electronic Technology Co., Ltd. has paid more attention to human resource recruitment. However, due to the short development time of the company, the system of various aspects is not mature, and the human resource recruitment has not been standardized and systematized. There are still some deficiencies in the recruitment process of the company, mainly in the following aspects:

\subsection{Incomplete Recruitment Plan}

Although most companies are aware of the importance of enterprise talent recruitment, the company's managers have insufficient understanding of human resource recruitment due to their own reasons, so they can't form a recruitment plan suitable for the actual situation of the enterprise. Some enterprise managers even don't have a recruitment plan. Only when there is a vacancy in the enterprise, they carry out job recruitment, which affects the normal operation of the enterprise. The recruitment of resources is random. Paijie company is a technical company, which has a large demand for employees in engineer related positions. However, the demand for employees of the company is determined subjectively by the managers, which is not only subjective and arbitrary, but also difficult to be consistent with the company's strategic objectives and long-term development plan.

\subsection{Interview Process not Standardized}

Interview is an important part of selecting candidates. If the interview process is not standardized, it is easy to lose the fairness and can't select the talents that meet the requirements of the enterprise. Paijie company has a more obvious single feature in personnel recruitment. During the interview, most of them take the way of face-to-face inquiry. For some positions with special requirements, there is no targeted interview method designed, which leads to the discovery that new employees do not meet the requirements 
of the position after entry, which wastes the company's human and material resources and financial resources. At the same time, it is difficult for the company to investigate the actual situation of the candidates through the interview. The value, character, ability and other elements of the candidates make the judgment of whether they are competent for the post biased.

\subsection{High Turnover Rate of Employees}

The turnover rate of the company's employees is relatively high, and it will greatly increase the company's cost and affect the company's efficiency. The turnover rate of employees in Pajie company is relatively large, which has a lot to do with unreasonable incentives. At present, the company is the pattern of monthly salary plus full-time bonus plus year-end bonus. In order to motivate employees, the company's year-end bonus accounts for a large proportion, while the monthly salary is relatively low. According to the two factor theory, employees' salary belongs to the health care factor, while employees' basic salary is relatively low, which will cause dissatisfaction among employees. The health care reason of salary didn't be satisfied, Even if the year-end bonus is higher, the incentive to employees is limited, and finally employees can only choose to leave the company.

\section{COUNTERMEASURES AND SUGGESTIONS ON RECRUITMENT OF SHENZHEN PAIJIE COMPANY}

Through the above analysis, we can know that there are three main problems in the human resource recruitment of Shenzhen paijie Electronic Technology Co., Ltd.: the recruitment plan is not perfect, the interview process is not standardized and the turnover rate is high. In view of these problems, the following countermeasures and suggestions are put forward.

\subsection{Make a Reasonable Recruitment Plan}

Reasonable recruitment plan plays an overall role in human resource recruitment of the company. If the company lacks recruitment plan, or the recruitment plan does not adapt to the development of the company, it will hinder the development of the company. The company shall formulate the company's short-term and long-term recruitment plan according to the company's development strategy, so as to continuously add vitality to the company's development. According to its own business characteristics, Pajie company plans positions in different directions, forecasts the company's short-term and long-term needs of personnel. In this process, it pays close attention to the company's organizational changes and market changes, and reduces the number of personnel and changes the personnel structure according to the specific situation.

\subsection{Constructing Interview Method Based on Competency Model}

The traditional interview method can only see the information on the resume of the candidate and some superficial features, but it can't understand the true situation of the deep-seated values, personality traits and other aspects of the candidate, and these deep-seated elements are often the key to whether the candidate is competent for the post. Based on the competency model for talent recruitment, we can identify the deep-seated characteristics of employees, which is more accurate, so the selected employees are more in line with the requirements of the post, and more able to adapt to the development of the enterprise. Paijie company should organize a team to analyze the work, define each position of the company, build a competency model, and apply the competency model elements of each position in the process of interview and recruitment.

\subsection{Improve the Incentive System}

According to Herzberg's two factor theory, health care factors will not bring satisfaction to people, while incentive factors will bring satisfaction to employees. In the development of the company, health care factors and incentive factors are indispensable. Health care factors can ensure the basic needs of employees and eliminate employees' dissatisfaction, while incentive factors can stimulate employees' working motivation and improve their working efficiency. The turnover rate of employees in Pajie company is relatively high, the health care factor of salary is not satisfied, and the proportion of year-end bonus is too large, so it is necessary to improve its incentive system, pay attention to human factors, understand the needs and motives of employees, and formulate incentive policies on this basis.

\section{CONCLUSION}

Human resource recruitment management is an indispensable part of an enterprise. Only by systematizing and standardizing the recruitment, can the enterprise keep updating its talents and increase its vitality and creativity.

\section{REFERENCES}

[1] Bai rengchu. Problems and Countermeasures in enterprise recruitment $[\mathrm{J}]$. Science and technology economic market, 2018, (11): 82-84.

[2] Liu Hongjuan. Problems and Countermeasures in human resource recruitment of enterprises in the new era $[\mathrm{J}]$. Modern marketing, 2018, (12): 169.

[3] Wang Li. Analysis on the effectiveness of recruitment channels in human resource management of pharmaceutical enterprises [J]. Communication research, 2018, (33): 222.

[4] Zhang Junlin. Application of competency model in enterprise recruitment [J]. Taxation, 2018, (36): 279.

[5] Bueno.C.M, Tubbs.S.L. Identifying Gobbal Leadership Compentencies: An Expbraory study[N]. Joumal of American Academy of Business Cambridge. Hollywood, 2004, 5(1): 80-87. 
[6] Barber.A.E, Rochling.M.V. Job Posting and Decision to Interview: A Verbal Protocol Analysis[J]. Journal of Applied Psychology, 1993, (78): 845-856.

[7] Herzberg.F, Mausner.B, Snyderman.B. The motivation to work[M]. New York: John Wiley \& Sons Inc, 1959: 20-35. [8] Herzberg.F, Mausner.B, Snyderman.B. The motivation to work[M]. New York: John Wiley \& Sons Inc, 1959: 20-35. 